\title{
Treatment of Pesticides in Wastewater by Heterogeneous and Homogeneous Photocatalysis
}

\author{
Catalina Daniela Stan, ${ }^{1}$ Igor Cretescu, ${ }^{2}$ Cristina Pastravanu, ${ }^{3}$ \\ Ioannis Poulios, ${ }^{4}$ and Maria Drăgan ${ }^{1}$ \\ ${ }^{1}$ Department of Drug Industry and Pharmaceutical Biotechnology, Grigore T. Popa University of Medicine and Pharmacy, \\ 16 Universitatii Street, 700115 Iasi, Romania \\ ${ }^{2}$ Department of Environmental Engineering and Management, Faculty of Chemical Engineering and Environmental Protection, \\ Gheorghe Asachi Technical University of Iasi, 73 Professor D. Mangeron Street, 700050 Iasi, Romania \\ ${ }^{3}$ Department of Materials Chemistry, "Al. I. Cuza" University of Iasi, 11 Carol I Boulvard, 700506 Iasi, Romania \\ ${ }^{4}$ Department of Chemistry, Aristotle University of Thessaloniki, 54124 Thessaloniki, Greece
}

Correspondence should be addressed to Igor Cretescu, icre@tuiasi.ro

Received 1 June 2012; Revised 10 August 2012; Accepted 21 August 2012

Academic Editor: Meenakshisundaram Swaminathan

Copyright (C) 2012 Catalina Daniela Stan et al. This is an open access article distributed under the Creative Commons Attribution License, which permits unrestricted use, distribution, and reproduction in any medium, provided the original work is properly cited.

\begin{abstract}
The effect of different heterogeneous and homogeneous photocatalytic systems on the oxidative degradation of mepiquat chloride in aqueous solutions was investigated. In the case of heterogeneous reactions, the influence of five factors was studied: the type of catalyst, photocatalyst concentration, $\mathrm{pH}$, pesticide concentration, and the presence of $\mathrm{H}_{2} \mathrm{O}_{2}$ and/or Fe ${ }^{3+}$. For homogeneous catalysis, other factors were studied: the oxidising agent and the light source. Nearly complete degradation of mepiquat chloride was obtained after about 180 minutes in the presence of an acid medium (pH3) using a UV-A lamp and TiO ${ }_{2} \mathrm{P}-25$ catalyst $(0.5 \mathrm{~g} / \mathrm{L})$, for an initial pesticide concentration of $10 \mathrm{ppm}$. Degradation rates corresponding to homogeneous photocatalysis were lower compared to those corresponding to the use of $\mathrm{TiO}_{2}$ as the photocatalyst.
\end{abstract}

\section{Introduction}

Removing refractory organic pollutants from wastewaters is an important issue given the fact that most of them are toxic, mutagenic, and/or carcinogenic, even in low concentrations, and are a real health threat to humans, animals, as well as to the environment [1]. Heterogeneous and homogeneous solar photocatalytic detoxification methods $\left(\mathrm{TiO}_{2} / \mathrm{H}_{2} \mathrm{O}_{2}\right.$, $\mathrm{Fe}^{+3} / \mathrm{H}_{2} \mathrm{O}_{2}$ ) have recently shown great promise for the treatment of industrial wastewater, groundwater, and contaminated air [2].

Mepiquat chloride or 1,1-dimethylpiperidine chloride, also known as DPC, is a new plant growth regulator that can be used on a variety of crops and exerts a variety of effects. It works by inhibiting gibberellic acid synthesis, reduces internode length, hastens maturity, and retards abscission [3]. In addition, DPC is used to prevent the lodging of winter wheat; for apples, it can increase calcium absorption, reduced by depression disease; for citrus, it can increase the sugar content. In agrochemical products, it is formulated as an emulsifiable concentrate, a water dispersible granulate and as a technical product. This pesticide was first registered in the USA in 1980 to be used as a growth regulator of cotton, and in 1997 it was reregistered by the Environmental Protection Agency (EPA) for its use in the USA [4]. Currently, it is formulated as an emulsifiable concentrate at concentrations lower than $5 \%(\mathrm{w} / \mathrm{v})$ [5].

Mepiquat chloride has the molecular formula $\mathrm{C}_{7} \mathrm{H}_{16} \mathrm{ClN}$ and a molecular weight of $149.66 \mathrm{~g} / \mathrm{mol}$. Figure 1 presents the structural formula of 1,1-dimethylpiperidine chloride.

Mepiquat chloride is labelled as a potential groundwater contaminant by the DPR (Department of Pesticide Regulation), because it has the potential to move into groundwater based on its water solubility, ability to bind to soils $\left(K_{\mathrm{oc}}\right)$, 


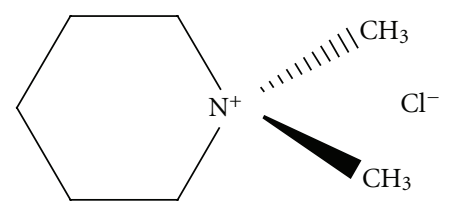

Figure 1: Structural formula of 1,1-dimethylpiperidine chloride.

and half-life. Its acute toxicity is classified as moderate by the IRIS (Integrated Risk Information System) of the US Environmental Protection Agency.

In recent years, new and more severe regulations coupled with enforcement against wastewater discharges have been established in most industrially developed countries [6]. This is why various technologies have been developed for the advanced treatment of wastewater containing pollutants that cannot be removed by conventional treatment processes. Destructive oxidation methods such as heterogeneous photocatalysis ( $\mathrm{TiO}_{2} / \mathrm{UV}-\mathrm{A}$ ), ozonation, $\mathrm{H}_{2} \mathrm{O}_{2} / \mathrm{UVB}$, photoFenton, and sonolysis are considered very attractive since they transform hazardous pollutants into compounds with a reduced impact on the environment [7]. Also, among advanced oxidation processes, homogeneous and heterogeneous photochemical oxidation processes have proven their efficiency in the degradation of refractory organic pollutants [8].

Photocatalysis implies the acceleration of a photoinduced reaction by the presence of a catalyst [9]. Photoinduced reactions are activated by the absorption of a photon with sufficient energy, that is, equal to or higher than the bandgap energy $\left(E_{\mathrm{bg}}\right)$ of the catalyst [10]. The absorption leads to a charge separation due to the promotion of an electron $\left(\mathrm{e}^{-}\right)$ from the valence band of the semiconductor catalyst to the conduction band, thus generating a hole $\left(\mathrm{h}^{+}\right)$in the valence band.

The activation equation can be written as:

$$
\mathrm{TiO}_{2}+\mathrm{h} v \longrightarrow \mathrm{h}^{+}+\mathrm{e}^{-}
$$

In this reaction, $\mathrm{h}^{+}$and $\mathrm{e}^{-}$are powerful oxidising and reducing agents, respectively. The oxidation and reduction reactions can be expressed as:

$$
\begin{aligned}
& \text { oxidation reaction: } \mathrm{h}^{+}+\mathrm{OH}^{-} \longrightarrow \mathrm{OH}^{\bullet} \\
& \text { reduction reaction: } \mathrm{e}^{-}+\mathrm{O}_{2 \text { ads }} \longrightarrow \mathrm{O}_{2 \mathrm{ads}}{ }^{-}
\end{aligned}
$$

In order to sustain a photocatalysed reaction, $\mathrm{e}^{-}-\mathrm{h}^{+}$ recombination subsequent to the initial charge separation must be prevented as much as possible [11].

Heterogeneous photocatalysis may be considered a viable alternative for the removal of refractory organics due to several important advantages such as: complete mineralization or formation of more readily biodegradable intermediates when complex organic compunds are treated, no need of auxiliary chemicals, no residual formation, easily operation and maintenance of the equipment [12].

Heterogeneous photocatalysis leads to the mineralisation of organic carbon using a semiconductor catalyst in suspension or as a thin film. One advantage of the photocatalytic process is its mild operating conditions and the fact that it can be powered by sunlight, thus significantly reducing the amount of electric power required and therefore the operating costs [13]. Heterogeneous photocatalysis is influenced by catalyst loading, initial pollutant concentration, $\mathrm{pH}$, radiant flux, aeration, the presence of other substances or impurities, and photoreactor geometry [14].

The most widely used semiconductor catalyst in photoinduced processes is titanium dioxide $\left(\mathrm{TiO}_{2}\right)$, because it is chemically and biologically inert, photocatalytically stable, relatively easy to produce and to use, able to efficiently catalyse reactions, cheap, and without risks to the environment or humans [15].

Homogeneous photocatalysis uses UV radiation in combination with chemical oxidising agents such as hydrogen peroxide or ozone.

\section{Experimental}

2.1. Light Sources. For the photocatalytic degradation of mepiquat chloride, a G23 Radium Ralutec UVA lamp (9W/ $78,350-400 \mathrm{~nm}, I=1.3517 \mathrm{ein} / \mathrm{min}$ ) and a Radium Ralutec VIS lamp $(9 \mathrm{~W} / 71, I=0.5898 \mathrm{ein} / \mathrm{min})$ were used.

Actinometry was used to determine the exact radiation intensity of both lamps within the vessels. The radiation intensities obtained for the UVA and the VIS lamp were $1.3517 \mathrm{ein} / \mathrm{min}$ and $0.3517 \mathrm{ein} / \mathrm{min}$, respectively. After 10-15 uses of the lamps, it was necessary to repeat the actinometric determinations to check that the lamp intensity remained constant.

2.2. Vessels and Reagents. For the photocatalytic experiments, a solution of mepiquat chloride pesticide was used. As catalysts, $\mathrm{TiO}_{2} \mathrm{P}-25, \mathrm{TiO}_{2} \mathrm{UV}-100, \mathrm{TiO}_{2}-\mathrm{A}, \mathrm{TiONa}$, and $\mathrm{ZnO}$ were studied.

A photochemical reactor (Figure 2) with volume of $500 \mathrm{~mL}$ was used to carry out the experimental tests. The reactor was covered with a black cloth to avoid interactions with ambient light.

2.3. Procedures and Analyses. In the initial $300 \mathrm{~mL}$ aqueous solution of the pesticide $(C=10 \mathrm{mg} / \mathrm{L})$, different quantities of catalysts were added. The reaction solutions were magnetically stirred in the dark for $30 \mathrm{~min}$ until adsorption/desorption equilibrium was reached. The solutions were then irradiated under UV light with continuous magnetic stirring. A fixed quantity of each mepiquat chloride solution was taken at regular time intervals during the illumination period and filtered through a syringe filter to analyse the amount of pesticide remaining in the solution. DPC concentrations during the experiments were monitored by a Total Organic Carbon Analyzer (Shimadzu), in order to measure the mineralisation of the pesticide.

\section{Results and Discussion}

3.1. Mepiquat Chloride Degradation by Heterogeneous Photocatalysis. The influence of five experimental factors was 


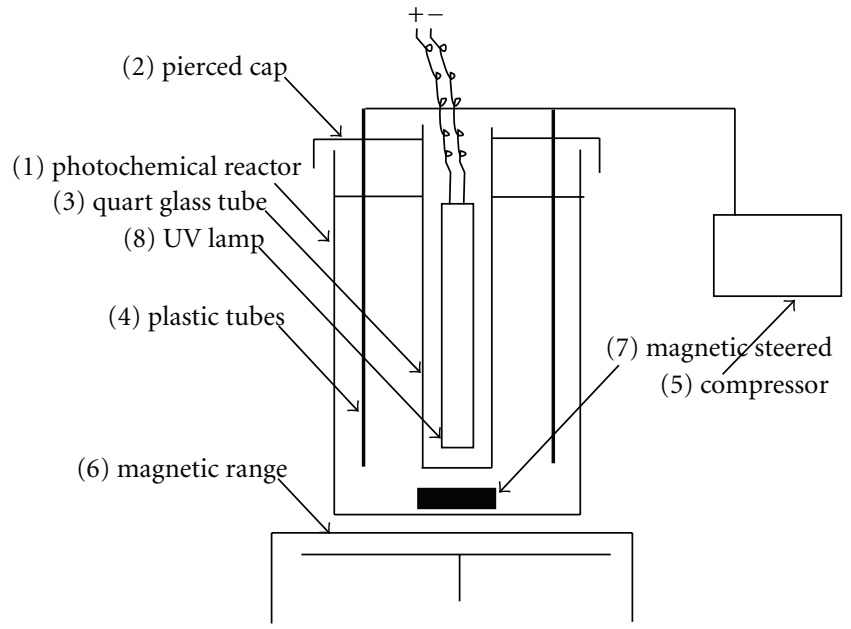

FIgUre 2: Photocatalysis experimental setup ((1) photochemical reactor, (2) pierced cap, (3) quart glass tube, (4) plastic tubes, (5) compressor, (6) magnetic range, (7) magnetic steered, (8) UV lamp).

studied: the type of catalyst, photocatalyst concentration, $\mathrm{pH}$, pesticide concentration, and the presence of $\mathrm{H}_{2} \mathrm{O}_{2}$ and/or $\mathrm{Fe}^{3+}$. The experiments were conducted by varying one factor and keeping the others constant.

3.1.1. Influence of the Type of Catalyst. Five types of catalysts were investigated in this study: $\mathrm{TiO}_{2} \mathrm{P}-25, \mathrm{TiO}_{2} \mathrm{UV}-100$, $\mathrm{TiO}_{2}-\mathrm{A}, \mathrm{TiONa}$, and $\mathrm{ZnO}$; the results are plotted in Figure 3.

The corresponding amounts of catalyst were added to $10 \mathrm{ppm}$ solutions of mepiquat chloride in order to obtain a dose of $0.5 \mathrm{~g}$ catalyst/L and then irradiated with UV-A light. From Figure 3, it can be seen that the $\mathrm{TiO}_{2} \mathrm{P}-25$ catalyst exhibited the best behaviour in the degradation of mepiquat chloride and was thus considered the reference catalyst. The increase of the TOC values in the case of the $\mathrm{ZnO}$ catalyst might be assigned to the desorption of the pesticide from the $\mathrm{ZnO}$ surface, taking into consideration that the adsorption of mepiquat chloride on this material is less intense in comparison with the other photocatalysts.

3.1.2. Influence of Catalyst Concentration. The influence of catalyst concentration was studied for the $\mathrm{TiO}_{2} \mathrm{P}-25$ catalyst, which was chosen as the reference.

The degradation experiments were conducted using the same pesticide concentration $(10 \mathrm{ppm})$, the same UV-A lamp, and different concentrations of the same photocatalyst. The results are depicted in Figure 4.

As expected, Figure 4 shows that the most advanced pesticide degradation occurred when heterogeneous photocatalysis was conducted with a higher dose of the catalyst $\left(\mathrm{TiO}_{2} \mathrm{P}-25\right)$.

3.1.3. Influence of $\mathrm{pH}$. The influence of the $\mathrm{pH}$ of the solution was studied by conducting the photocatalyst experiments with $0.5 \mathrm{~g} / \mathrm{L} \mathrm{TiO} 2 \mathrm{P}-25$ catalyst in $10 \mathrm{ppm}$ mepiquat chloride solution, using the UV-A lamp but adjusting the solution $\mathrm{pH}$

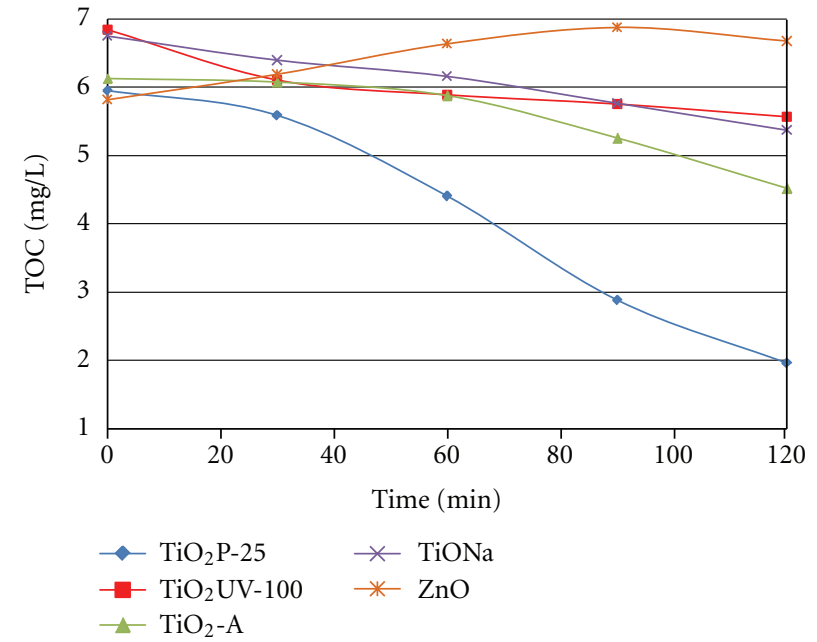

FIgure 3: Pesticide degradation by heterogeneous photocatalysis using different catalysts (initial conditions: $10 \mathrm{ppm}$ mepiquat chloride, $0.5 \mathrm{~g} / \mathrm{L}$ catalyst, UV-A lamp).

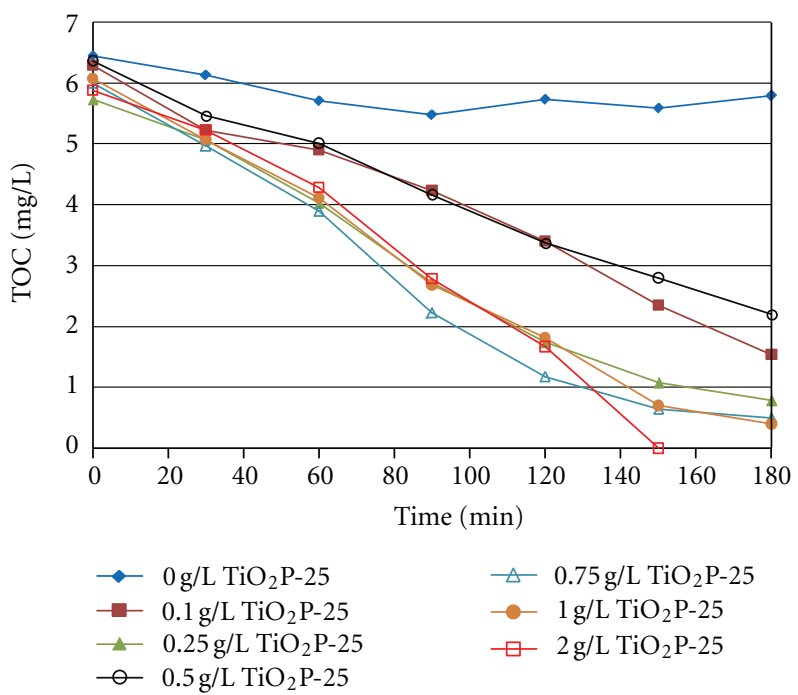

Figure 4: The $\mathrm{TiO}_{2} \mathrm{P}-25$ dose influence on the degradation of mepiquat chloride (initial conditions: $10 \mathrm{ppm}$ mepiquat chloride, $0.5 \mathrm{~g} / \mathrm{L} \mathrm{TiO}_{2} \mathrm{P}-25$, UV-A lamp).

from acidic values ( $\mathrm{pH} 3,4$, and 5) to basic values ( $\mathrm{pH} 8,9$, and 11)

Figure 5 illustrates the variation in $\mathrm{TOC} / \mathrm{TOC}(0)$ values over time at different $\mathrm{pH}$ values. The positive effect of acidic $\mathrm{pH}$ on pesticide degradation noted in the figure can be assigned to the fact that the $\mathrm{TiO}_{2}$ surface is positively charged when the solution $\mathrm{pH}$ is lower than 6.8 , thus facilitating the photocatalytic process [9].

3.1.4. Influence of the Mepiquat Chloride Concentration. The influence of the mepiquat chloride concentration on the photocatalytic process was studied using the $\mathrm{TiO}_{2} \mathrm{P}-25$ catalyst. The degradation experiments were conducted using pesticide solutions of various initial concentrations, the same 


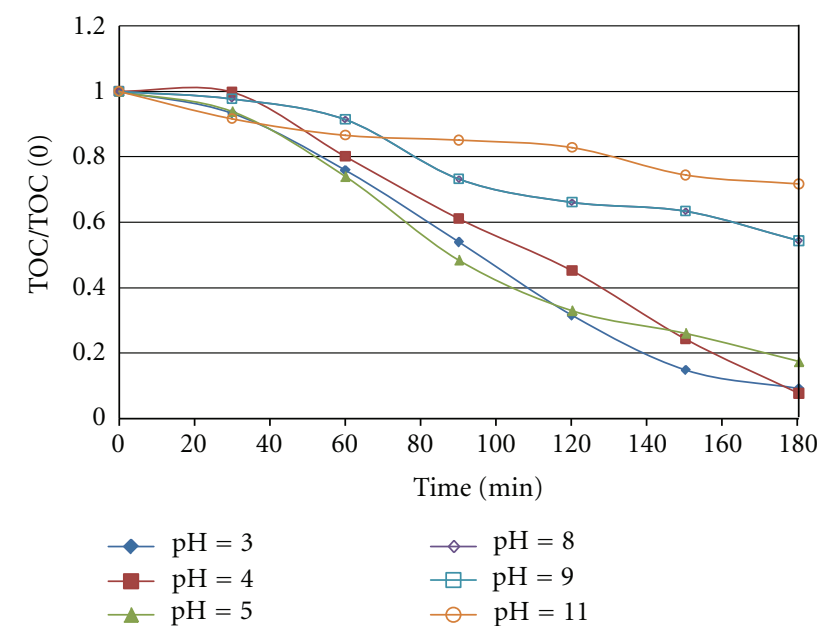

Figure 5: Pesticide degradation over time at different $\mathrm{pH}$ values of the initial solution (initial conditions: $10 \mathrm{ppm}$ mepiquat chloride, $0.5 \mathrm{~g} / \mathrm{L} \mathrm{TiO}_{2} \mathrm{P}-25$, UV-A lamp).

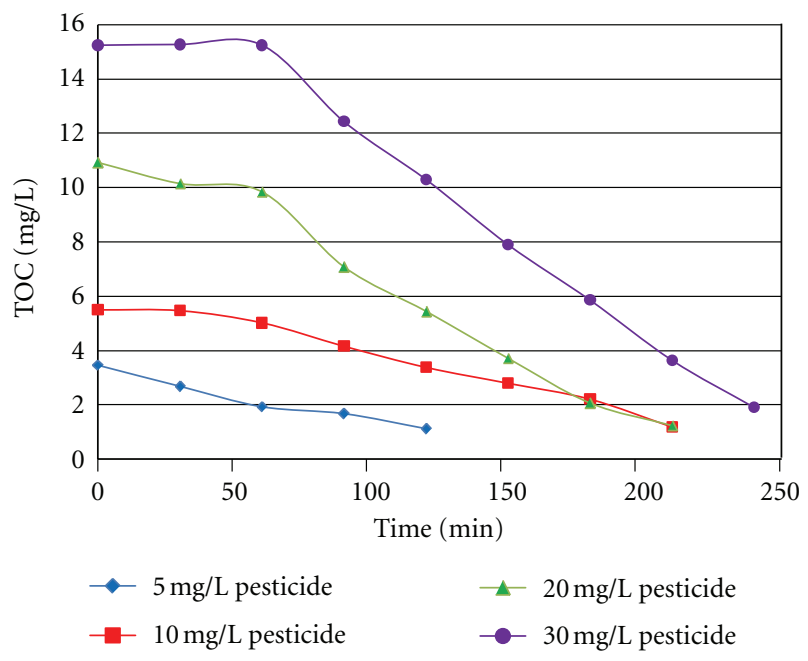

Figure 6: Behaviour of different concentrations pesticide solutions during heterogeneous photocatalysis using UV-A light and $0.5 \mathrm{~g} / \mathrm{L}$ $\mathrm{TiO}_{2} \mathrm{P}-25$ as the catalyst.

UV-A lamp, and the same photocatalyst concentration $(0.5 \mathrm{~g} / \mathrm{L})$. The results are shown in Figure 6.

3.1.5. The Influence of $\mathrm{H}_{2} \mathrm{O}_{2}$ or $\mathrm{Fe}^{+3}$. The next step of this study focused on enhancing the photocatalysis reaction by adding $\mathrm{H}_{2} \mathrm{O}_{2}$ or $\mathrm{Fe}^{+3}$ in different concentrations to the initial solution.

Figures 7 and 8 show pesticide degradation during photocatalysis with $\mathrm{TiO}_{2} \mathrm{P}-25$, facilitated by $\mathrm{H}_{2} \mathrm{O}_{2}$ and $\mathrm{Fe}^{+3}$, respectively. The best degradation rate was obtained when the $\mathrm{TiO}_{2} \mathrm{P}-25$ photocatalysis was used alone. It was noted that no enhancement was obtained by adding $\mathrm{H}_{2} \mathrm{O}_{2}$ or $\mathrm{Fe}^{+3}$ at any dose.

3.2. Mepiquat Chloride Degradation by Homogeneous Photocatalysis. Homogeneous photocatalytic oxidation of the

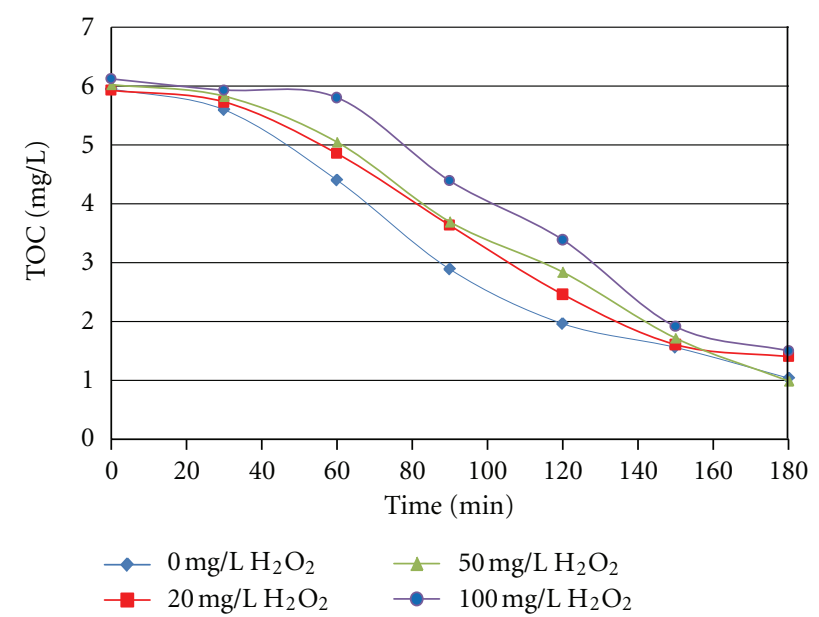

FIGURE 7: Heterogeneous photocatalysis of mepiquat chloride in the presence of $\mathrm{TiO}_{2} \mathrm{P}-25$ and $\mathrm{H}_{2} \mathrm{O}_{2}$ (initial conditions: $10 \mathrm{ppm}$ mepiquat chloride, $0.5 \mathrm{~g} / \mathrm{L} \mathrm{TiO}_{2} \mathrm{P}-25$, UV-A lamp).

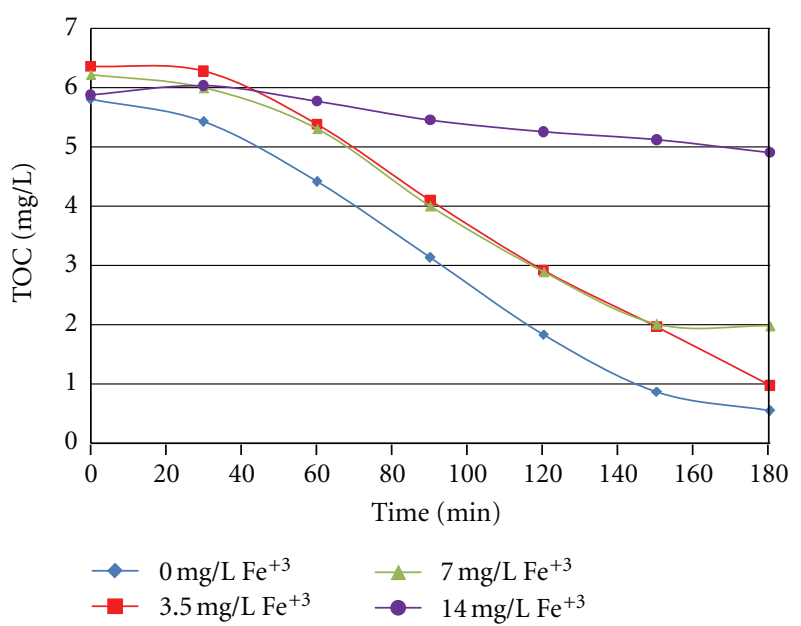

FIGURE 8: Heterogeneous photocatalysis of mepiquat chloride in the presence of $\mathrm{TiO}_{2} \mathrm{P}-25$ and $\mathrm{Fe}^{+3}$ (initial conditions: $10 \mathrm{ppm}$ mepiquat chloride, $0.5 \mathrm{~g} / \mathrm{L} \mathrm{TiO}{ }_{2} \mathrm{P}-25$, UV-A lamp).

pesticide was also tested using two oxidising agents: a photo-Fenton agent $\left(\mathrm{H}_{2} \mathrm{O}_{2}+\mathrm{Fe}^{+3}\right)$ and a ferrioxalate agent (potassium oxalate $+\mathrm{H}_{2} \mathrm{O}_{2}+\mathrm{Fe}^{+3}$ ) in various concentrations. The influence of light was also studied using UV-A and VIS lamps, respectively. The results are depicted in Figures 9 and 10 , respectively.

In the case of the photo-Fenton reagent, the best results were obtained when less oxidant was used: $50 \mathrm{ppm} \mathrm{H}_{2} \mathrm{O}_{2}$ and $3.5 \mathrm{ppm} \mathrm{Fe}^{+3}$. When more photo-Fenton agent was used, lower values for pesticide decontamination were obtained.

With the ferrioxalate reagent, an excellent degradation rate was obtained when visible light was used, as can be seen in Figure 11, this being economically reliable. When using the UV-A lamp, photodegradation results were comparable with those achieved for photo-Fenton homogeneous catalysis. 


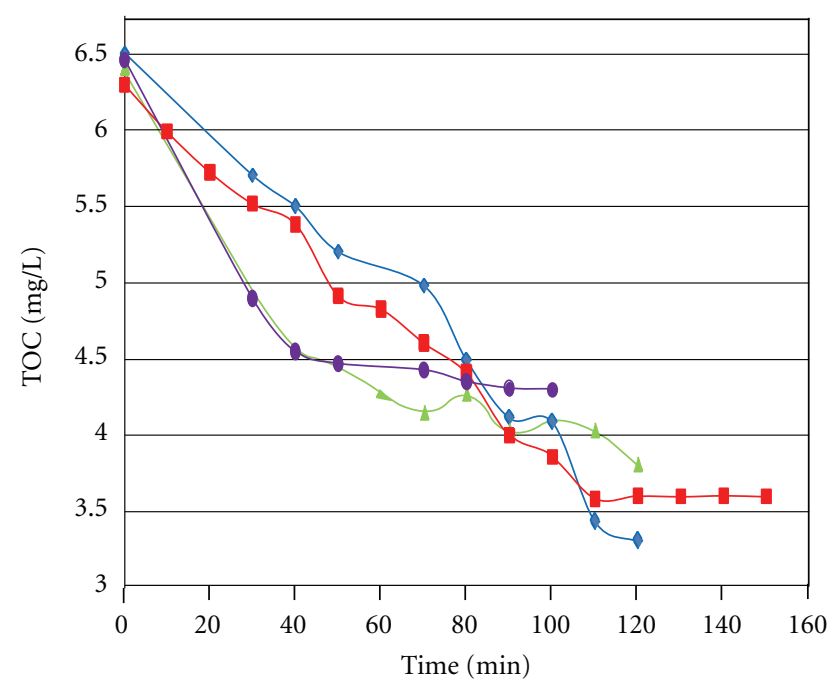

$\smile 50 \mathrm{ppm} \mathrm{H}_{2} \mathrm{O}_{2} ; 3.5 \mathrm{ppm} \mathrm{Fe}^{+3} \longrightarrow 50 \mathrm{ppm} \mathrm{H}_{2} \mathrm{O}_{2} ; 14 \mathrm{ppm} \mathrm{Fe}^{+3}$

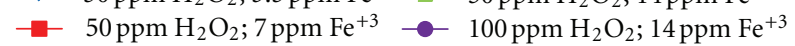

FIGURE 9: Homogeneous photocatalysis of mepiquat chloride using the photo-Fenton agent (initial conditions: $10 \mathrm{ppm}$ mepiquat chloride, UV-A lamp).

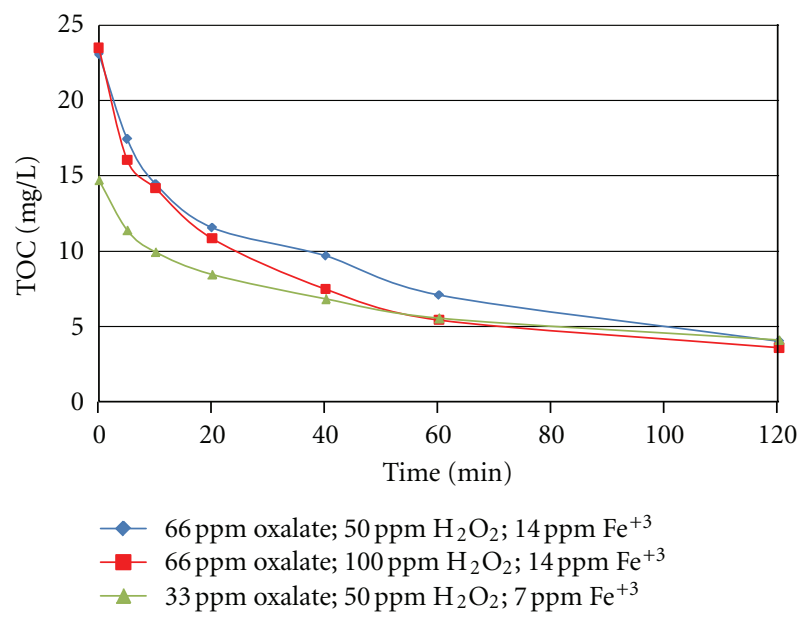

FIgURe 10: Homogeneous photocatalysis of mepiquat chloride using the ferrioxalate agent (initial conditions: $10 \mathrm{ppm}$ mepiquat chloride, $0.5 \mathrm{~g} / \mathrm{L} \mathrm{TiO}_{2} \mathrm{P}-25$, UV-A lamp).

\section{Conclusions}

(i) The present study demonstrated the possibility of oxidative degradation of persistent organic pesticides by heterogeneous photocatalysis.

(ii) Nearly complete degradation of mepiquat chloride was obtained after about 180 minutes in the presence of an acid medium (pH3) using a UV-A lamp and the $\mathrm{TiO}_{2} \mathrm{P}-25$ catalyst $(0.5 \mathrm{~g} / \mathrm{L})$, for an initial pesticide concentration of $10 \mathrm{ppm}$.

(iii) The remnant pesticide concentrations were higher when homogeneous photocatalytic oxidation was involved, in comparison with levels obtained in a

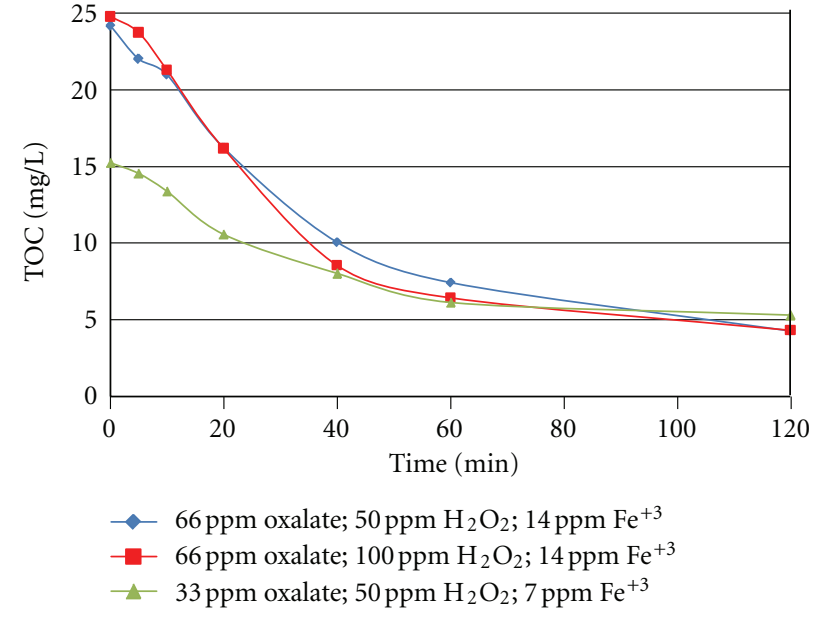

Figure 11: Homogeneous photocatalysis of mepiquat chloride using the ferrioxalate agent (initial conditions: $10 \mathrm{ppm}$ mepiquat chloride, VIS lamp).

heterogeneous photocatalytic degradation process based on $\mathrm{TiO}_{2}$.

(iv) Degradation rates corresponding to homogeneous photocatalysis were lower compared to those corresponding to the use of $\mathrm{TiO}_{2}$ as the photocatalyst. In this way, the remnant concentrations of mepiquat chloride were below the drinking water level of comparison for acute and chronic risk range for infants and children $(6 \mathrm{ppm})$, but as a consequence of the heterogeneous photocatalysis degradation process, this remnant concentration was about 10 times lower than the abovementioned level $(0.54 \mathrm{ppm}$ for $0.5 \mathrm{~g} / \mathrm{L}$ $\mathrm{TiO}_{2} \mathrm{P}-25, C_{i}=10 \mathrm{ppm}$ pesticide).

(v) Moreover, we tested the possibility of reusing $\mathrm{TiO}_{2} \mathrm{P}$ 25 three times and found comparable photocatalytic activity for the solids with each use. The $\mathrm{TiO}_{2}$ Degussa was recovered by simple washing, providing an economic advantage to this process.

(vi) Our study succeeded in achieving the task of finding a suitable photocatalytic system to provide a mepiquat chloride remnant concentration in accordance with EPA standards.

\section{References}

[1] I. Poulios, E. Micropoulou, R. Panou, and E. Kostopoulou, "Photooxidation of eosin Y in the presence of semiconducting oxides," Applied Catalysis B, vol. 41, no. 4, pp. 345-355, 2003.

[2] G. D. Suditu, M. Secula, C. G. Piuleac, S. Curteanu, and I. Poulios, "Genetic algorithms and neural networks based optimization applied to the wastewater decolorization by photocatalytic reaction," Revista de Chimie, vol. 59, no. 7, pp. 816$825,2008$.

[3] 2012, http://chemyq.com/.

[4] 2012, http://www.epa.gov/oppsrrd1/REDs/factsheets/.

[5] G. Quintás, S. Garrigues, A. Pastor, and M. de la Guardia, "FTRaman determination of Mepiquat chloride in agrochemical 
products," Vibrational Spectroscopy, vol. 36, no. 1, pp. 41-46, 2004.

[6] M. S. Secula, G. D. Suditu, I. Poulios, C. Cojocaru, and I. Cretescu, "Response surface optimization of the photocatalytic decolorization of a simulated dyestuff effluent," Chemical Engineering Journal, vol. 141, no. 1-3, pp. 18-26, 2008.

[7] A. F. Caliman, C. Cojocaru, A. Antoniadis, and I. Poulios, "Optimized photocatalytic degradation of Alcian Blue 8 GX in the presence of $\mathrm{TiO}_{2}$ suspensions," Journal of Hazardous Materials, vol. 144, no. 1-2, pp. 265-273, 2007.

[8] S. Kaniou, K. Pitarakis, I. Barlagianni, and I. Poulios, "Photocatalytic oxidation of sulfamethazine," Chemosphere, vol. 60, no. 3, pp. 372-380, 2005.

[9] A. Mills and S. Le Hunte, "An overview of semiconductor photocatalysis," Journal of Photochemistry and Photobiology A, vol. 108, no. 1, pp. 1-35, 1997.

[10] O. Carp, C. L. Huisman, and A. Reller, "Photoinduced reactivity of titanium dioxide," Progress in Solid State Chemistry, vol. 32, no. 1-2, pp. 33-177, 2004.

[11] I. Poulios, M. Kositzi, K. Pitarakis, S. Beltsios, and I. Oikonomou, "Photocatalytic oxidation of methomyl in the presence of semiconducting oxides," International Journal of Environment and Pollution, vol. 28, no. 1-2, pp. 33-44, 2006.

[12] A. F. Caliman, C. Teodosiu, and I. Balasanian, "Aplications of heterogeneous photocatalysis for industrial wastewater treatment," Environmental Engeneering and Management Journal, vol. 1, pp. 187-196, 2002.

[13] I. Poulios, A. Avranas, E. Rekliti, and A. Zouboulis, "Photocatalytic oxidation of Auramine $\mathrm{O}$ in the presence of semiconducting oxides," Journal of Chemical Technology and Biotechnology, vol. 75, no. 3, pp. 205-212, 2000.

[14] C. Betianu, F. A. Caliman, M. Gavrilescu, I. Cretescu, C. Cojocaru, and I. Poulios, "Response surface methodology applied for Orange II photocatalytic degradation in $\mathrm{TiO}_{2}$ aqueous suspensions," Journal of Chemical Technology and Biotechnology, vol. 83, no. 11, pp. 1454-1465, 2008.

[15] C. Pastravanu, I. Poulios, E. Popovici, and I. Cretescu, "A case study of textile wastewater treatment by heterogeneous photocatalytic degradation," The Annals of the "Dunarea de Jos" University of Galati Fascicle II-Mathematics, Physics, Chemistry, Informatics, vol. 32, pp. 31-38, 2009. 


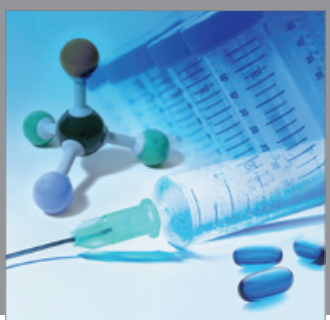

International Journal of

Medicinal Chemistry

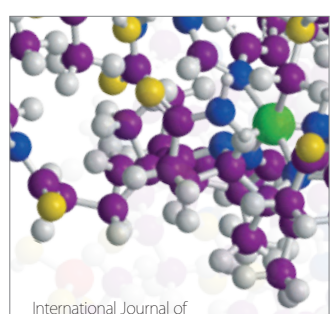

Carbohydrate Chemistry

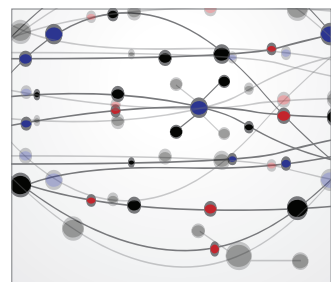

The Scientific World Journal
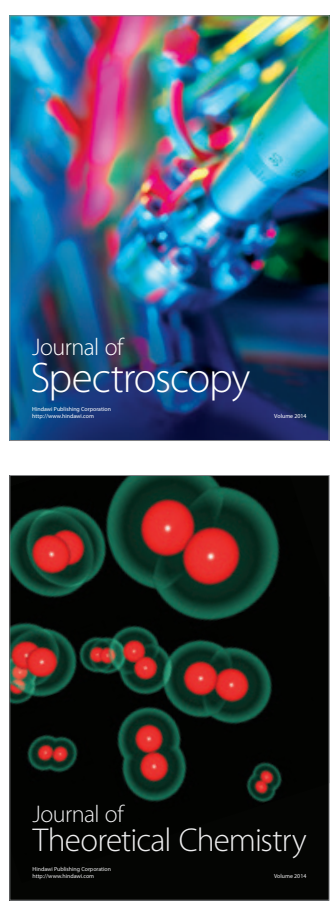
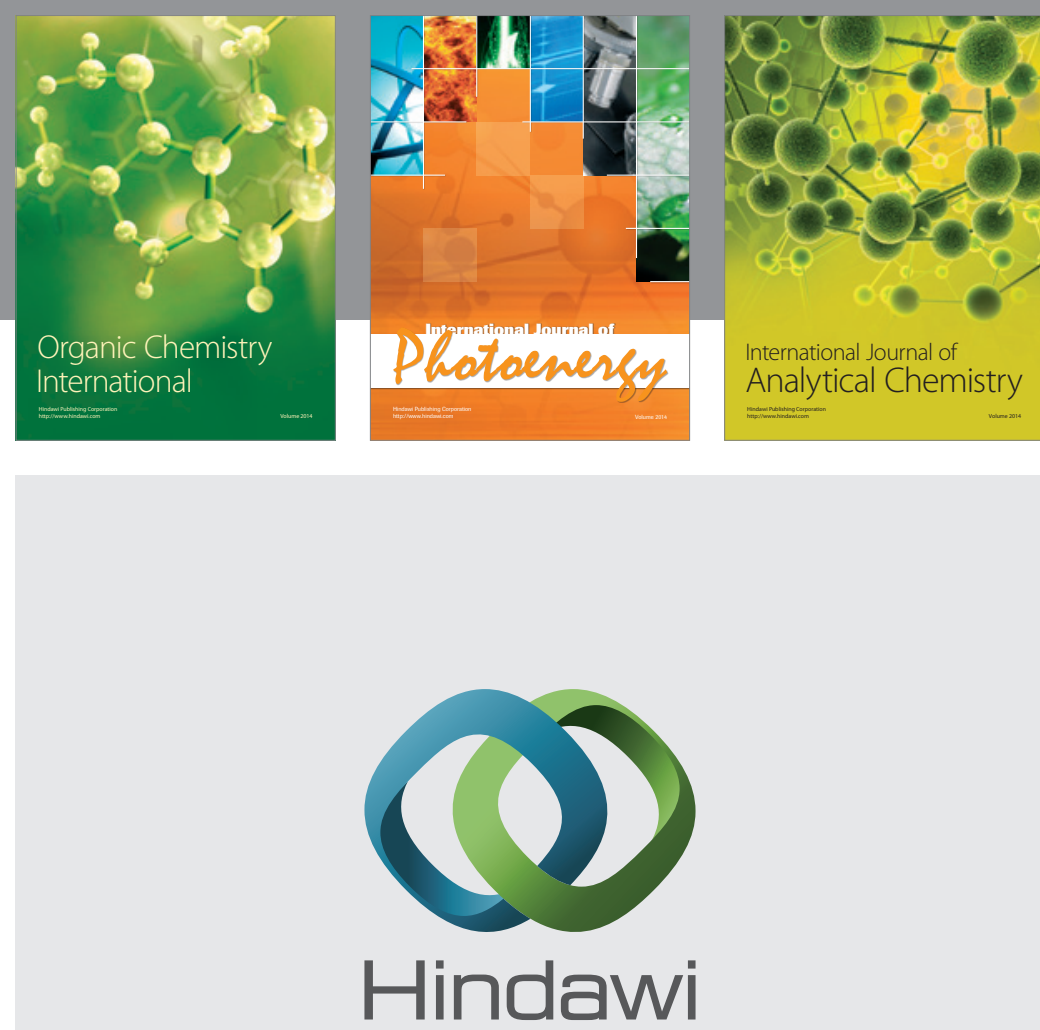

Submit your manuscripts at

http://www.hindawi.com
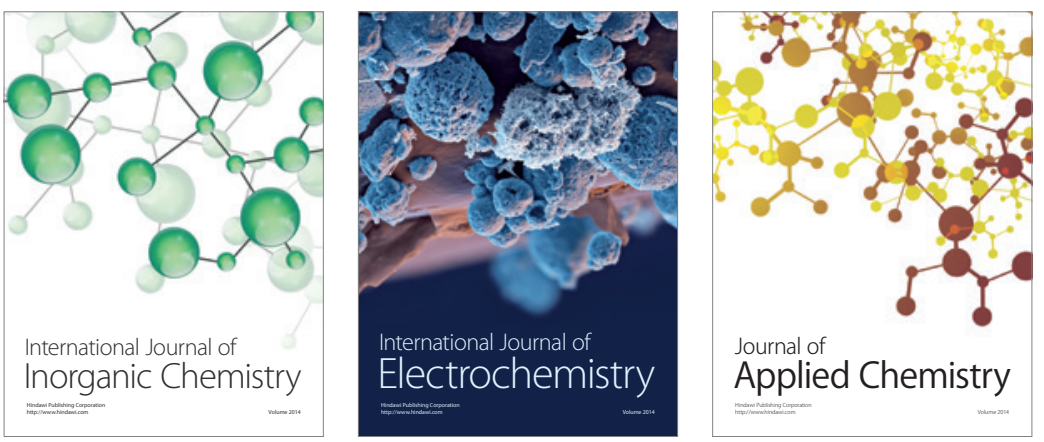

Journal of

Applied Chemistry
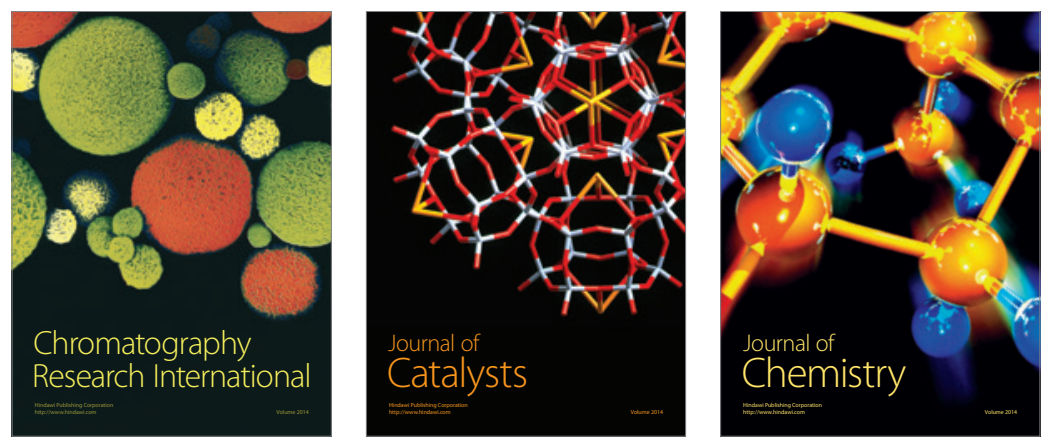
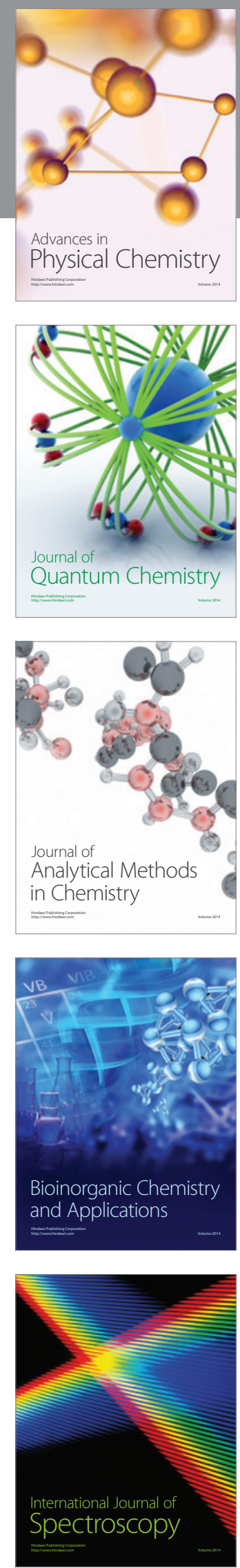